\title{
A Comparative Study of Critical Success Factors for General and Healthcare Business Intelligence Systems
}

\author{
Quy Nguyen \\ Faculty of Information Systems \\ University of Information Technology, Ho Chi Minh City \\ Email: qnd2611@gmail.com \\ Rob Meredith \\ Faculty of Information Technology \\ Monash University \\ Caulfield East, Victoria \\ Email: Rob.Meredith@monash.edu \\ Frada Burstein \\ Faculty of Information Technology \\ Monash University \\ Caulfield East, Victoria \\ Email: $\underline{\text { Frada.Burstein@monash.edu }}$
}

\section{Abstract}

Critical Success Factor (CSF) research provides a useful instrument for better managing a project and driving it to success. Research about CSFs for business intelligence (BI) systems and industry-specific CSFs have been noted; however, scant research has been conducted to investigate CSFs for healthcare BI projects. This paper adopted a mixed method approach to investigate differences between CSFs of BI systems in general and BI systems in the healthcare industry. We found that although CSFs of healthcare $\mathrm{BI}$ are similar to those of general BI, there is a significant overlap between CSFs for BI development and use. This finding supports the intertwined relationship between success of different BI project phases, which has yet been acknowledged in BI and IS success models.

Keywords Critical Success Factors, Healthcare Business Intelligence, Business Intelligence Success Model. 


\section{Introduction}

According to Negash and Gray (2008), business intelligence (BI) is a type of information system (IS) that gathers, stores, manages and analyses data to provide inputs to and improve outputs of the decisionmaking process. The term "business intelligence" has been around for many decades and since the 2000s, BI has become a significant part of IT portfolios of many organisations (Arnott and Pervan 2014). Gartner (2017) forecasts that global spending on BI technologies will reach US\$22.8 billion at the end of 2020.

In healthcare organisations, BI adoption has made significant impacts on administrative and clinical operations. These systems are often used by medical professionals to obtain aggregated data from multiple information registries and medical records to gain better understandings of healthcare practices, and improve patient outcomes (Tremblay et al. 2012). BI applications also improve healthcare administration by increasing process efficiency, better utilising the human resource and reducing costs (Foshay and Kuziemsky 2014). Despite the strategic role of BI and significant investments for BI projects, organisations often suffer from high rates of failure. Healthcare BI projects face even more significant challenges due to the involvement of diverse stakeholders, and the risk-averse and complex nature of the healthcare setting (Standing and Cripps 2015). Brooks et al. (2013) point out that unlike BI systems in other industries, healthcare BI systems need to gather data from multiple siloed systems within the organisation as well as external entities because of interoperability requirements in healthcare practices. Adding to the complexity of healthcare BI is the need to integrate financial data and clinical data which are often stored in various formats and have different definitions. These challenges justify a desire to investigate key factors that are likely to affect the overall success of healthcare BI projects. Unfortunately, our understanding of this topic is still limited.

This paper is, therefore, motivated by both theoretical and practical objectives. Theoretically, given the lack of empirical studies on CSFs of healthcare BI, our paper makes an initial step toward addressing this research gap by adding empirical evidence to the question of whether CSFs of healthcare BI are different from general BI. We were also interested in identifying CSFs for different project phases as Wu (2007) and Sangar and Iahad (2013) argue that success should be defined differently for each phase. While different projects may consist of different lifecycle phases, we investigated the broad difference between development CSFs and use CSFs. In practical terms, the investigation of CSFs of healthcare BI is expected to help BI practitioners and healthcare organisations better focus their efforts and resources on critical areas to drive their projects to success throughout the entire project lifecycle.

To achieve the research objectives, we integrated the literature on CSFs of BI and related decision support systems to create a list of BI CSFs. This general BI CSF list was used as a theoretical lens for our exploration of CSFs for healthcare-specific BI projects. In addition to an online survey, we conducted face to face interviews with healthcare BI experts to gain in-depth understandings of the impact of healthcare settings on BI projects. Our research results confirmed that CSFs for healthcare BI are similar to CSFs for general BI, and there is a significant overlap between CSFs of BI development and BI use. On the basis of our analysis, we offered significant insights to the current understandings on success models of BI projects, and practical implications on how to maintain BI success across different project phases.

\section{Research Design}

As stated in section 1, this paper aims to investigate CSFs for healthcare BI and the relationship between CSFs and different project phases. To achieve these objectives, an exploratory, interpretivist approach was adopted. Specifically, this research followed a mixed-method research design with both qualitative and quantitative elements. According to Remus and Wiener (2010), the combination of quantitative and qualitative approaches is especially relevant and useful to CSF research consisting of multiple phases with each phase requiring a different method. The mixed-method approach was applied in the three stages of this research as follows:

\subsection{Stage one - Literature review}

The purpose of stage one was to explore and identify a set of CSFs for BI projects across multiple industries, discussed in previous studies. We conducted a systematic review of the CSF literature in several online databases such as ProQuest, EBSCOHost, Google Scholar, and the AIS electronic library. Also, acknowledging the fact that BI is a type of decision support system (DSS) (Arnott and Pervan 2014) and research findings of different types of DSS are transferrable (Clark et al. 2007), this research utilised 


\begin{tabular}{|l|l|c|}
\hline \multicolumn{1}{|c|}{ Research phase } & \multicolumn{1}{|c|}{ Purpose } & $\begin{array}{c}\text { Type of } \\
\text { research }\end{array}$ \\
\hline Literature review & $\bullet \begin{array}{l}\text { Constructing a theoretical basis for CSF } \\
\text { examination. } \\
\text { Identifying and defining a CSF list for general BI } \\
\text { Classifying CSFs into different phases of BI projects }\end{array}$ & Qualitative \\
\hline $\begin{array}{l}\text { Online survey of healthcare } \\
\text { BI experts }\end{array}$ & $\begin{array}{l}\text { Assessing the relevance of the CSFs of general BI for } \\
\text { healthcare settings }\end{array}$ & $\begin{array}{l}\text { Quantitative } \\
\& \\
\text { qualitative }\end{array}$ \\
\hline $\begin{array}{l}\text { Semi-structured interviews } \\
\text { with healthcare BI experts }\end{array}$ & $\begin{array}{l}\text { Obtaining in-depth insight of issues raised in the } \\
\text { survey's responses. } \\
\text { Triangulate the survey results. }\end{array}$ & Qualitative \\
\hline
\end{tabular}

Table 1: Research design applied in three stages of this research

CSF findings for such DSS as executive information systems, data warehouses, and personal DSS to ensure that the list was exhaustive. The result of this stage was an integrated list of CSFs for general BI, which was used as a theoretical lens for our exploration of the CSFs for healthcare-specific BI.

\subsection{Stage two - An online survey}

Based on the CSF list of general BI, a semi-structured survey was designed to collect data from healthcare BI developers and users, using an online survey tool. The first part of the survey collected demographic information from the respondents to ensure that they met the inclusion criteria. The second part asked respondents to indicate the 'criticality' of the identified CSFs to healthcare BI development, as well as use on five-point Likert scales. The third part consisted of open-ended questions asking the respondents to provide any CSFs that might have been missing from the CSF list. The survey link was posted to an online professional network where it reached more than 1300 healthcare BI practitioners internationally. During the survey time, email reminders and the snowballing technique were applied to gain respondent rates. A total of nine usable survey responses were collected.

\subsection{Stage three - Follow-up interviews}

At the end of the survey, the respondents were asked if they would like to participate in follow-up interviews. Two respondents agreed and were selected. The interviewees were selected because they had substantial experience of healthcare BI and BI in other industries. Both of them were working as healthcare BI experts for a large public hospital in Australia. Before the actual interviews, interview questions were emailed to the interviewees for them to prepare for the interview so that more informative data could be collected and interview fluidity was maintained (Poon and Wagner 2001). The interviews were conducted for between 60 to 75 minutes and were audio recorded. In addition to the audio records, written notes were taken during the interviews and later analysed.

\section{Theoretical Background and Related Works}

\subsection{Bl success and critical success factors}

BI success can be understood as positive benefits obtained through the deployment of ISs (Isik et al. 2013). However, because success is perceived differently, and organisations implement ISs for different objectives, IS success is measured in different ways. As a result, several success models have been developed to measure IS success such as the model of Delone and McLean (2003) and Data Warehouse (DW) success such as the work of Wixom and Watson (2001). Also, as mentioned in Section 1, Wu (2007) and Sangar and Iahad (2013) argue that success measures should be defined according to project stages because as the project progresses, success changes. Following Delone and McLean (2003), Wixom and Watson (2001), and Yeoh and Koronios (2010), success criteria for BI implementations may include factors such as information quality, system quality, service quality and project process performance, while BI use success may take into account system use and net benefits.

The success of BI projects can be affected by various factors. The idea of CSFs is that some factors are so critical that they must be effectively managed for the project to be successful (Rockart 1979), these factors must be addressed effectively for the organisation be successful. Since Rockart's article, many studies have been conducted to investigate CSFs for BI in different industries such as insurance and financial services Arnott (2008), energy (Harison 2012; Yeoh and Koronios 2010), and transportation and construction (Yeoh and Koronios 2010). 
According to Remus and Wiener (2010), one of the key characteristics of CSF research is the need to analyse CSFs in specific contexts. CSF literature reveals several results for BI in different industries, however, our understanding of this topic in healthcare settings still remains limited. In addition, although the dynamic and interrelated nature of CSFs has been acknowledged in previous studies (McBride 1997; Nandhakumar 1996), they do so in a limited way. Therefore, the purpose of our literature review is to compile CSFs for BI projects from previous studies into an integrated list of CSFs for general $\mathrm{BI}$ and present this list as a theoretical lens for the exploration of CSFs for healthcare BI. Also, acknowledging the dynamic and interrelated nature of CSFs, we have categorised the identified CSFs into three groups: BI development, BI use, and CSFs common to both phases. This categorisation creates a basis for further investigation of the relationship between CSFs of different phases and the implications it may have on BI success dimensions.

\subsection{CSFs for general BI development}

Analysing executive information system (EIS) and the DW literature, Arnott (2008) created a list of 10 CSFs for BI and DW systems. His CSF list includes appropriate team skills, effective data management, widespread management support, committed and informed executive sponsor, appropriate technology, adequate resources, a clear link with business objectives, well-defined information and systems requirements, evolutionary development, and management of project scope. ) developed a list of 22 CSFs including 15 CSFs specific to BI and seven CSFs common to both BI and enterprise resource planning systems. Yeoh and Koronios (2010) created a list of seven CSF categories for BI implementation. BI literature also reveals other CSF lists such as Olszak and Ziemba (2012), Olbrich et al. (2012), and Sangar and Iahad (2013).

\subsection{CSFs for general $\mathrm{BI}$ use}

When investigating CSFs for EIS, Rainer and Watson (1995) developed two CSF lists for the development phase and the use phase. Their CSF list for EIS use consisted of 46 factors in four main groups: system function, systems characteristics, information quality factors, and impact on executive work factors. Later, Sangar and Iahad (2013) found that perceived usefulness and learnability, and userfriendly technologies are essential to end-user acceptance, making it a CSF of BI use. In addition, organisational maturity was considered critical to the continual re-alignment of BI and the organisation's business objectives (Schieder and Gluchowski 2011; Wixom and Watson 2010). Similarly, Audzeyeva and Hudson (2016) claim that organisations should effectively manage organisational deep structure factors such as core beliefs and values, organisational structures, power distribution and control systems to derive long-term benefits from their BI investment.

\subsection{CSFs common to general $\mathrm{BI}$ development and general $\mathrm{BI}$ use}

Wixom and Watson (2001) contend that after successful implementation, widespread management support and ongoing commitment of resources continue to be critical to the success of the postimplementation phase of DW. Moreover, because business and information requirements evolve over time, BI systems need to be updated to support the on-going re-alignment between BI and the organisation (Audzeyeva and Hudson 2016). Therefore, an adaptive, evolutionary development methodology (Arnott 2008; Poon and Wagner 2001) is another CSF common to both BI development and BI use. User training was considered as another common CSFs for both BI development and BI use because users can improve satisfaction and expertise in deploying the BI system through training sessions (Poon and Wagner 2001; Sangar and Iahad 2013).

\subsection{An integrated list of general BI CSFs}

An integrated list of 23 CSFs was obtained after an extensive search of CSFs in the literature as shown in Table 1. The CSF list was obtained from a variety of academic sources, including peer-reviewed articles, conference papers, and book chapters. However, to ensure the quality of the reference sources, only peer-reviewed articles were selected to create the list.

\begin{tabular}{|c|c|l|}
\hline No. & CSF & \multicolumn{1}{c|}{ Description } \\
\hline CSF1 & $\begin{array}{c}\text { Ongoing top } \\
\text { management support } \\
\text { and sponsorship }\end{array}$ & $\begin{array}{l}\text { BI/DW should receive widespread and ongoing support and } \\
\text { sponsorship from top management. This helps manage the } \\
\text { change process and overcome resistance. }\end{array}$ \\
\hline CSF2 & $\begin{array}{c}\text { Clear link with business } \\
\text { objectives }\end{array}$ & $\begin{array}{l}\text { BI projects must be aligned and driven by business requirements } \\
\text { and strategies. BI systems need to be re-aligned to fulfill changing } \\
\text { business needs. }\end{array}$ \\
\hline
\end{tabular}




\begin{tabular}{|c|c|c|}
\hline No. & CSF & Description \\
\hline $\mathrm{CSF}_{3}$ & $\begin{array}{l}\text { Adaptive, evolutionary } \\
\text { development approach }\end{array}$ & $\begin{array}{l}\text { A successful DW/BI system should be developed iteratively with } \\
\text { strong user involvement, evolving towards an effective } \\
\text { application set. }\end{array}$ \\
\hline $\mathrm{CSF} 4$ & User training & $\begin{array}{l}\text { BI projects should have proper training programs for users and } \\
\text { focus on training super users who will then train other users in } \\
\text { their department. }\end{array}$ \\
\hline CSF5 & Appropriate team skills & $\begin{array}{l}\text { The project manager must possess adequate knowledge and skills } \\
\text { in business and technical areas to successfully guide the project. } \\
\text { Support staff must be capable of mastering technologies required } \\
\text { for the system. }\end{array}$ \\
\hline CSF6 & $\begin{array}{l}\text { Appropriate technology } \\
\text { and tools }\end{array}$ & $\begin{array}{l}\text { BI hardware and software should be selected with a high level of } \\
\text { organisational fit. }\end{array}$ \\
\hline CSF7 & Adequate resources & $\begin{array}{l}\text { BI projects must receive sufficient budget for software, hardware, } \\
\text { and human resources. }\end{array}$ \\
\hline CSF8 & Data quality and integrity & $\begin{array}{l}\text { The project should have an effective ETL process to minimise } \\
\text { data quality issues and integrate data from different sources. }\end{array}$ \\
\hline CSF9 & $\begin{array}{l}\text { Well-defined information } \\
\text { and } \\
\text { system requirements }\end{array}$ & $\begin{array}{l}\text { BI project should have common definitions of what is required } \\
\text { from the systems, and these definitions should be agreed by both } \\
\text { business and technical sides. }\end{array}$ \\
\hline CSF10 & $\begin{array}{l}\text { Scalable and flexible } \\
\text { technical framework }\end{array}$ & $\begin{array}{l}\text { Technical infrastructure must be scalable to facilitate system } \\
\text { expansion to align with evolving information needs. }\end{array}$ \\
\hline CSF11 & $\begin{array}{l}\text { Effective project } \\
\text { management }\end{array}$ & $\begin{array}{l}\text { The project should be guided by an effective, suitable } \\
\text { management methodology to minimise project risks and increase } \\
\text { the success chance. }\end{array}$ \\
\hline CSF12 & $\begin{array}{l}\text { Integration of BI and } \\
\text { other systems }\end{array}$ & $\begin{array}{l}\text { Physical or functional link of BI with various systems and their } \\
\text { application or data should be visible so that the derived value can } \\
\text { be greater than that obtained from individual systems. }\end{array}$ \\
\hline CSF13 & Change management & $\begin{array}{l}\text { Organisations need to adopt an effective approach to managing } \\
\text { changes associated with the BI implementation. }\end{array}$ \\
\hline CSF14 & Effective communication & $\begin{array}{l}\text { BI projects should develop an effective communication plan to } \\
\text { communicate to internal and external audience. This is to convey } \\
\text { information to and to get feedback from the intended audience. }\end{array}$ \\
\hline CSF15 & $\begin{array}{l}\text { Balanced team skill and } \\
\text { composition }\end{array}$ & $\begin{array}{l}\text { BI projects should include people from both the IT and the } \\
\text { business side of the organisation. }\end{array}$ \\
\hline CSF16 & Human factor & $\begin{array}{l}\text { Apart from having a balanced development team, BI projects } \\
\text { should find right people as project champions and participants in } \\
\text { pilot projects. }\end{array}$ \\
\hline CSF17 & Timing of BI effort & $\begin{array}{l}\text { The readiness of organisations to accept changes from the } \\
\text { adoption of BI systems. }\end{array}$ \\
\hline CSF18 & Perceived BI usefulness & Users' perception of how BI can help to fulfill their daily work. \\
\hline CSF19 & Organisational maturity & $\begin{array}{l}\text { Development level of structures and processes of organisations } \\
\text { which facilitate strategic use of BI to address business priorities. }\end{array}$ \\
\hline CSF2O & Organisational culture & $\begin{array}{l}\text { The system of beliefs, values, and norms of individuals within } \\
\text { organisations that supports the use of BI systems and fosters it by } \\
\text { emphasizing their economic and operational benefits. }\end{array}$ \\
\hline CSF21 & $\begin{array}{l}\text { Information quality } \\
\text { factors }\end{array}$ & $\begin{array}{l}\text { Quality of information obtained from the systems which include } \\
\text { timeliness, accuracy, relevance, and convenience }\end{array}$ \\
\hline CSF22 & BI function factors & $\begin{array}{l}\text { Functions of the systems that provide useful information for } \\
\text { users. They include status access, standardised definitions, } \\
\text { exception reporting, access to external data, drilling down. }\end{array}$ \\
\hline CSF23 & BI characteristics factors & $\begin{array}{l}\text { Attributes of the system that allow users to easily access and } \\
\text { assimilate information. They include ease of use, adaptable } \\
\text { interface, adaptability to changing information requirements }\end{array}$ \\
\hline
\end{tabular}

Table 2: An integrated CSF list for general BI

It should be acknowledged that the identified CSFs are a very large list. This would seem to contradict the underlying premise of CSFs, which is that they should consist of "the limited number of areas" critical to success (Rockart 1979). Also, some CSFs in this list, such as CSF11, CSF13, CSF14, appears to be 
relevant because they were discussed at different levels of detail in previous studies. For example, some studies grouped detailed factors into more general and comprehensive CSFs such as Rainer and Watson (1995) and Yeoh (2010) while others listed detailed factors as separate CSFs such as Olbrich et al. (2012). These suggest two issues in CSF research: CSF grouping and the size of CSF lists which are beyond the scope of this study but warrants further consideration in future studies. For the sake of exhaustiveness, we refrained from editing the integrated list, instead relying on the survey and interview phases of the project to identify the 'criticality' of each identified CSF.

The 23 identified CSFs were categorised into three groups: common CSFs, CSFs for BI development, and CSFs for BI use. It should be noted that the categorisation was based on research findings in previous studies where they have been found critical to the success of either BI development, BI use, or both phases. Four CSFs were included as common CSFs, thirteen CSFs as specific to BI development and eight CSFs as specific to BI use. Table 3 presents the categorisation, along with the sources used as the basis for classification.

\begin{tabular}{|c|c|c|c|}
\hline $\begin{array}{l}\text { CSF } \\
\text { No. }\end{array}$ & Development & Use & $\begin{array}{c}\text { CSF } \\
\text { categorisation }\end{array}$ \\
\hline CSF1 & $\begin{array}{l}\text { (Poon and Wagner 2001); (Yeoh and } \\
\text { Koronios 2010); (Presthus et al. 2012); }\end{array}$ & $\begin{array}{l}\text { (Wixom and Watson 2001); } \\
\text { (Grubljesic and Jaklic 2015) }\end{array}$ & Common \\
\hline CSF2 & $\begin{array}{l}\text { (Yeoh and Koronios 2010); (Olszak and } \\
\text { Ziemba 2012); (Sangar and Iahad 2013) }\end{array}$ & (Audzeyeva and Hudson 2016) & Common \\
\hline $\mathrm{CSF}_{3}$ & $\begin{array}{l}\text { (Poon and Wagner 2001); (Presthus et al. } \\
\text { 2012) }\end{array}$ & (Audzeyeva and Hudson 2016) & Common \\
\hline $\mathrm{CSF}_{4}$ & (Harison 2012); (Presthus et al. 2012) & $\begin{array}{l}\text { (Sangar and Iahad 2013); } \\
\text { (Grubljesic and Jaklic 2015) }\end{array}$ & Common \\
\hline CSF5 & $\begin{array}{l}\text { (Presthus et al. 2012); (Olszak and Ziemba } \\
\text { 2012); (Sangar and Iahad 2013) }\end{array}$ & & Development \\
\hline CSF6 & $\begin{array}{l}\text { (Wixom and Watson 2001); (Olszak and } \\
\text { Ziemba 2012); (Sangar and Iahad 2013) }\end{array}$ & & Development \\
\hline CSF7 & $\begin{array}{l}\text { (Wixom and Watson 2001); (Harison } \\
\text { 2012); (Olszak and Ziemba 2012) }\end{array}$ & & Development \\
\hline CSF8 & $\begin{array}{l}\text { (Wixom and Watson 2001); (Yeoh and } \\
\text { Koronios 2010); (Olszak and Ziemba } \\
\text { 2012); (Sangar and Iahad 2013) }\end{array}$ & & Development \\
\hline CSF9 & $\begin{array}{l}\text { (Rainer and Watson 1995); (Poon and } \\
\text { Wagner 2001); (Olszak and Ziemba 2012) }\end{array}$ & & Development \\
\hline CSF10 & (Yeoh and Koronios 2010); (Harison 2012) & & Development \\
\hline CSF11 & (Sangar and Iahad 2013) & & Development \\
\hline CSF12 & (Olszak and Ziemba 2012); (Islk et al. 2013) & & Development \\
\hline CSF13 & $\begin{array}{l}\text { (Yeoh and Koronios 2010); (Olszak and } \\
\text { Ziemba 2012) }\end{array}$ & & Development \\
\hline $\begin{array}{l}\text { CSF14, } \\
16,17\end{array}$ & (Presthus et al. 2012) & & Development \\
\hline CSF15 & $\begin{array}{l}\text { (Yeoh and Koronios 2010); (Presthus et al. } \\
\text { 2012) }\end{array}$ & & Development \\
\hline CSF18 & & $\begin{array}{l}\text { (Sangar and Iahad 2013); } \\
\text { (Grubljesic and Jaklic 2015) }\end{array}$ & Use \\
\hline CSF19 & & $\begin{array}{l}\text { (Wixom and Watson 2010); } \\
\text { (Audzeyeva and Hudson 2016) }\end{array}$ & Use \\
\hline CSF2O & & $\begin{array}{l}\text { (Harison 2012); (Grubljesic } \\
\text { and Jaklic 2015) }\end{array}$ & Use \\
\hline $\begin{array}{l}\text { CSF21, } \\
22,23\end{array}$ & & (Rainer and Watson 1995) & Use \\
\hline
\end{tabular}

Table 3 : A categorisation of CSFs for general BI 


\section{Survey and Interviews}

\subsection{Survey data analysis}

The survey received a total of twelve responses, of which three were excluded because of missing data, resulting in nine useable responses. While the sample size is very low, it should be noted that the purpose of the survey was qualitative and exploratory rather than quantitative and seeking to establish statistical validity. Rather, our aim was to gain an in-depth understanding of the healthcare context and how it affects the success of BI projects from senior experts in the area, with significant collective experience across multiple projects.

The respondents worked in different healthcare departments. Most had more than five years of experience in healthcare BI projects and were involved in more than one project phase.

\begin{tabular}{|c|l|c|}
\hline \multicolumn{2}{|l|}{ Respondent characteristics } & $\begin{array}{c}\text { No. of respondent } \\
\mathbf{N}=\mathbf{9}\end{array}$ \\
\hline \multirow{4}{*}{ Job title } & Manager of IT department & 5 \\
\cline { 2 - 3 } & Manager of business department & 2 \\
\cline { 2 - 3 } & Manager of R\&D department & 1 \\
\cline { 2 - 3 } & Healthcare Solution Architect & 1 \\
\hline \multirow{3}{*}{ Healthcare BI experience } & $1-5$ years & 1 \\
\cline { 2 - 3 } & $5-10$ years & 7 \\
\cline { 2 - 3 } & More than 10 years & 1 \\
\hline \multirow{2}{*}{ Role in healthcare BI project } & Developer & 7 \\
\cline { 2 - 3 } & User & 7 \\
\hline \multirow{2}{*}{ Healthcare BI project phase involved } & Development & 7 \\
\cline { 2 - 3 } & Use & 2 \\
\hline
\end{tabular}

Table 4: Survey respondents' demographic information.

Respondents were asked to rate the importance of each CSF for the healthcare BI project using a fivepoint Likert scale from not important at all (1) to absolutely critical (5). During the data analysis, the rating was sorted into two groups for comparison. We categorised an individual response as considering a CSF as critical if it was rated 4 or 5 . With nine responses, we classified a factor as critical if it was rated critical by five or more respondents. Figure 1 provides a visual summary of this analysis.

DEVELOPMENT PHASE

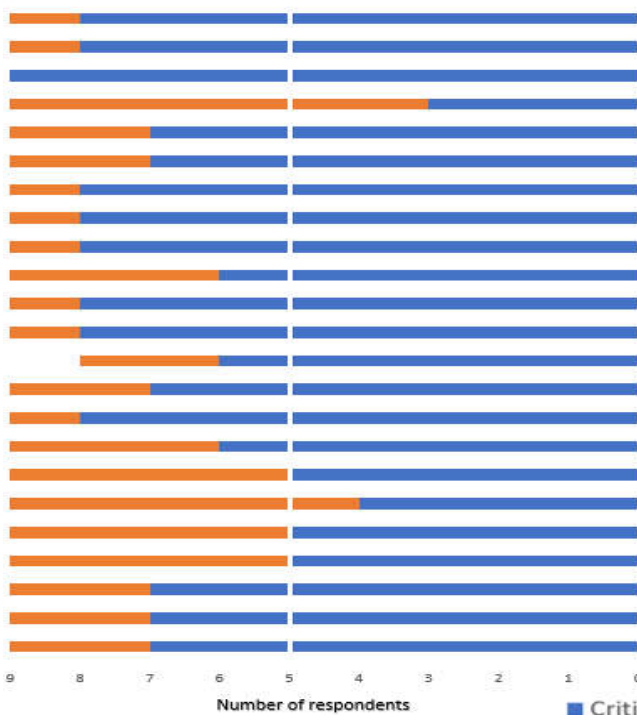

CSF1

CSF2

CSF3

CSF4

CSF5

CSF6

CSF7

CSF8

CSF9

CSF10

CSF11

CSF12

CSF13

CSF14

CSF15

CSF16

CSF17

CSF18

CSF19

CSF2O

CSF21

CSF22

CSF23

Figure 1: CSF rating for healthcare BI development and use.

Based on this analysis, changes were made to the CSF categorisation. Two CSFs were not rated as critical for healthcare BI development: CSF4 (user training), and CSF18 (perceived BI usefulness). CSF4 was 
originally a common CSF; however, the survey suggests that it is only critical to BI use. The result of this analysis is, therefore, that all CSFs, except for CSFO4 and CSF18 are common to both development and use phases. Only CSFo 4 and CSF 18 belong to the use category. These findings suggest that it may not be possible to distinguish CSFs clearly by phase for healthcare BI projects.

At the end of the survey, the respondents were asked to identify CSF differences between healthcare BI and general BI. One distinctive feature of healthcare BI, provided by the respondent, is the ability to benchmark BI results with other healthcare organisations. This is not because of competitive or financial purposes, but is to "share and improve clinical practice and KPIs across the sector". Survey respondents also highlighted the difficulties in benchmarking healthcare BI systems due to incompatible data formats, definitions, and business rules. Although the importance of BI benchmarking in healthcare BI projects were acknowledged by the survey respondents, there are still questions about how BI benchmarking contributes to the success of healthcare BI projects, and whether this factor is a CSF or it is just an important factor. These questions are discussed further in the follow-up interviews.

\subsection{Interview data analysis}

As outlined above, follow-up interviews were sought to further understand issues that arose from the survey, with respondents volunteering their willingness to participate at the end of the survey. Two healthcare BI experts working in a large public hospital in Australia were chosen, with their backgrounds described in Table 4.

\begin{tabular}{|l|l|l|}
\hline & \multicolumn{1}{|c|}{ Interviewee 1 } & \multicolumn{1}{c|}{ Interviewee 2 } \\
\hline Current job role & Business service manager & $\begin{array}{l}\text { Director of application \& } \\
\text { knowledge management }\end{array}$ \\
\hline Experience with healthcare BI & 6 years & $5^{1 / 2}$ years \\
\hline Role in healthcare BI project & Designer & Designer \\
\hline $\begin{array}{l}\text { Previous experience with BI } \\
\text { systems in other industries }\end{array}$ & $-\quad \begin{array}{l}\text { 3 years } \\
\text { Financial service industry }\end{array}$ & $\begin{array}{l}\text { S years } \\
\text { Software industry }\end{array}$ \\
\hline
\end{tabular}

Table 5: Backgrounds of the interview participants.

The interviewees believed that changes in the CSF categorisation reflect current practice in the BI industry. For them, BI development is an ongoing process in which the BI team needs to redevelop the system continuously to remain relevant to business requirements. The first interviewee commented:

As I mentioned before, BI development phase is an iterative process and it's ongoing all of the time to have a relevant business intelligent system that needs to be responsive to what the users need which means the development phase never really finishes.

According to the interviewees, because BI development and BI use are intertwined, many CSFs became critical to the success of both phases. In explaining this relationship, apart from arising business requirements, the introduction of new BI technology was mentioned as one key reason. BI technological advancements enable the BI system to deal with more complex data sources and to fulfill requirements that were previously unsolvable. The second interviewee related:

I think what has occurred is that the technology is much more agile and much more open to being able to attach to different data sources and data sets that put it into that common domain now whereas several years ago. I would say that the approach has changed significantly over the last five to seven years.

In seeking to explain their opinions on the reasons for changes in the CSF categorisation, two examples were given by the interviewees. First, $\mathrm{CSF}_{9}$ (well-defined information, and system requirements), which was originally categorised as a development phase CSF, is a common CSF because changes in users' information needs require the BI team to continually redefine new information needs and adjust the system accordingly. The first participant contended:

To me, it's like information system requirement will change over time. It's not like oh I installed a system in 2000 that will go to the end of the world it is not it will be like the requirement of that system, the specification, will always be changing.

Second, CSF2o (organisational culture) which was classified as a CSF for BI use, was argued by the interviewees to be common to both phases because organisations should have a culture that supports 
data management before, during and after the BI system is developed. Without this culture, the BI project will suffer from data quality issues and therefore face the risk of failure. The second interviewee commented:

Within our environment, data are collected long before it gets used. In the BI area, there needs to be an organisational culture that takes into account the need to inform people that changes need to occur and there needs to be a data stewardship that is implemented across the organisation from a governance perspective.

In regard to $\mathrm{CSF}_{4}$ (user training), originally classified as common to both phases, the interviewees questioned the need of user training during the development phase because key users need to be involved in the development team from scratch. They often became experts of the BI tool through this involvement and therefore formal training was only necessary for general users when the BI system was deployed. The first interviewee said:

Users are heavily engaged in all steps in the development so without training the users are getting a good feeling about that tool... In this case, a bunch of super users who are really into that business need are already familiar with the tool.

According to the interviewees, changes in the CSF categorisation were caused by BI evolution and new BI technologies. For them, these triggers exist in many industries rather than being specific to the healthcare context. The first interviewee contended: "I would agree much more with CSF changes you got from the survey across multiple industries."

In discussing benchmarking BI results between healthcare organisation, the interviewees considered this is a distinctive feature of healthcare BI as opposed to general BI. In healthcare sector, sharing information and data is a common practice to help improve clinical and research activities whereas commercial BI systems may find it difficult to exchange BI results which are often of operational and strategic importance. Both interviewees also acknowledged the significance of benchmarking practice to the development of healthcare BI systems in two different ways. First, by benchmarking BI results, users can have visual guidance on what features and functions of the BI systems they would like to have. Second, this practice facilitates knowledge sharing between development teams which improves the performance of the BI project. The interviewees, however, just considered BI benchmarking is an important factor rather than a CSF of healthcare BI as expressed in the first interviewee's comment: "It may not be a critical success factor but it is one of the factors that you should utilise while developing your BI tool."

\section{Discussion and Conclusion}

To date, little research has been devoted to exploring the distinction between CSFs for BI development and BI use, although the interaction between success factors across different project stages has been recognised previously. The IS success model of Delone and McLean (2003) is among the most prominent works describing the relationship between success dimensions. In their model, Delone and McLean (2003) argue that "information quality", "system quality" and "service quality" are three separate measures that affect "system use" and "user satisfaction". "Use" and "user satisfaction" are considered to be in an interrelationship in which positive system use will result in user satisfaction and greater satisfaction will encourage users to use the system more frequently. "System use" and "user satisfaction" will bring "net benefits", which, in turn, will affect "system use" and "user satisfaction". In another popular success model of data warehousing systems, Wixom and Watson (2001) argue that implementation success can be measured by organisational, project, and implementation dimensions and these dimensions will affect system quality which will then lead to net benefits. These models, even the consolidated model for BI success of Schieder and Gluchowski (2011), neglected to include the impacts of system use on the success of system implementation success although they acknowledged the influence of implementation success dimensions on system deployment success. The impact of system use on the success of system development was apparent in our data as most of the CSFs were considered critical for both project phases. This intertwined relationship is a result of the evolutionary nature of BI development. Success models for BI projects, therefore, should be updated and validated to recognise the blurred line between system use and system development: the linear development process assumed in models such as Delone and Mclean's may mean that these models do not apply to systems developed through evolutionary processes.

To our knowledge, this was the first research to investigate differences between CSFs of healthcare BI and general BI. The need to research CSFs according to specific industries has been raised since the study of Rockart (1979) and then Leidecker and Bruno (1984). These authors argue that in corporate 
management, the success of companies within the same industry is often determined by a small number of similar CSFs. Our research, however, found that CSFs of healthcare BI are similar to general BI and that the list of CSFs from the literature is surprisingly large. Despite the size of the list, participants didn't suggest that any of the CSFs were not, in fact, critical. This finding may suggest that the impact of industrial characteristics can be stronger in the field of corporate management where different industries may result in different sets of CSFs. When it comes to BI implementation and deployment, the impact of organisational, technical, and project management factors become more significant to the success of BI projects. It should be noted that this finding does not necessarily negate the need to consider specific industry characteristics in tailoring BI projects, which, according to Chiasson and Davidson (2005), can influence the implementation or practice, use, and impacts of IT artefacts such as BI systems. Instead, the finding highlights the need to distinguish other important, but perhaps not critical factors from CSFs. In fact, in our research BI benchmarking was considered to have significant impacts on the success of healthcare BI development as it fosters learning process between users, the systems and developers. This learning cycle is a central concept in the iterative and evolutionary development of DSS (Keen 1980). BI benchmarking is a distinctive feature of healthcare BI as a result of the collaborative nature in clinical and research practice between healthcare organisations. Whereas, BI benchmarking is limited in other commercial sectors due to the competitiveness between companies and strategic importance of BI results that are often securely protected. Although BI benchmarking was not considered as a CSF in this research, this factor can affect the success of healthcare BI and therefore worth consideration of healthcare BI practitioners and users when developing their BI systems.

With the research findings, our study has made theoretical contributions to our understanding on CSFs of BI projects in different industries and important implications for BI practice. It has also identified the problematic nature of CSF research in the fact that the integrated list of CSFs identified from the literature is so broad and large. Theoretically, before this study, little research was conducted investigating CSFs for healthcare BI although several studies on CSFs for BI in other industries have been conducted. Our study addressed this research gap by providing evidence that despite the unique characteristics of the healthcare industry, general BI CSFs apply. Our research findings have therefore contributed to CSF research for general BI by verifying it in a new industry. Findings on the distinction between CSFs for BI development and BI use have highlighted the integrated nature of evolutionary BI development and raised questions about assumptions of linear development processes in common IS success models. For BI practice, healthcare organisations that are using or planning to implement BI systems can use our research findings to guide their projects. The verification of the 23 CSFs in healthcare settings can assist BI practitioners in understanding what factors should be managed well and focus their finite resources and efforts to these areas. Our work also alerts BI practitioners that CSFs of BI development may continue to influence the success of BI use and vice versa. Therefore, these factors should be managed well even after the BI systems have been implemented to achieve overall success.

Our findings are of course limited due to the limited number of survey responses. Therefore, our findings are not generalisable in a positivist sense. Rather, they offer insight for directions of future research into IS success models and the problems inherent in CSF studies.

\section{References}

Arnott, D. 2008. "Success Factors for Data Warehouse and Business Intelligence Systems," ACIS 2008 Proceedings, p. 16.

Arnott, D., and Pervan, G. 2014. "A Critical Analysis of Decision Support Systems Research Revisited: The Rise of Design Science," Journal of Information Technology (29:4), pp. 269-293.

Audzeyeva, A., and Hudson, R. 2016. "How to Get the Most from a Business Intelligence Application During the Post Implementation Phase? Deep Structure Transformation at a Uk Retail Bank," European Journal of Information Systems (25:1), pp. 29-46.

Brooks, P., El-Gayar, O., and Sarnikar, S. 2013. "Towards a Business Intelligence Maturity Model for Healthcare," System Sciences (HICSS), 2013 46th Hawaii International Conference on: IEEE, pp. 3807-3816.

Chiasson, M. W., and Davidson, E. 2005. "Taking Industry Seriously in Information Systems Research," Mis Quarterly (29:4), pp. 591-605.

Clark, T. D., Jones, M. C., and Armstrong, C. P. 2007. "The Dynamic Structure of Management Support Systems: Theory Development, Research Focus, and Direction," Mis Quarterly (31:3), pp. 579-615.

Delone, W. H., and McLean, E. R. 2003. "The Delone and Mclean Model of Information Systems Success: A Ten-Year Update," Journal of management information systems (19:4), pp. 9-30. 
Foshay, N., and Kuziemsky, C. 2014. "Towards an Implementation Framework for Business Intelligence in Healthcare," International Journal of Information Management (34:1), pp. 20-27.

Gartner. 2017. "Gartner Says Worldwide Business Intelligence and Analytics Market to Reach \$18.3 Billion in 2017." Retrieved 12 July 2017, from http://www.gartner.com/newsroom/id/3612617

Grubljesic, T., and Jaklic, J. 2015. "Business Intelligence Acceptance: The Prominence of Organizational Factors," Information Systems Management (32:4), pp. 299-315.

Harison, E. 2012. "Critical Success Factors of Business Intelligence System Implementations: Evidence from the Energy Sector," International Journal of Enterprise Information Systems (IJEIS) (8:2), pp. 113.

Hawking, P., and Sellitto, C. 2010. "Business Intelligence (Bi) Critical Success Factors," 21st Australian Conference on Information Systems.

Isık, O., Jones, M. C., and Sidorova, A. 2013. "Business Intelligence Success: The Roles of Bi Capabilities and Decision Environments," Information \& Management (50:1), pp. 13-23.

Keen, P. G. 1980. "Adaptive Design for Decision Support Systems," ACM SIGOA Newsletter (1:4-5), pp. 1525 .

Leidecker, J. K., and Bruno, A. V. 1984. "Identifying and Using Critical Success Factors," Long range planning (17:1), pp. 23-32.

McBride, N. 1997. "The Rise and Fall of an Executive Information System: A Case Study," Information Systems Journal (7:4), pp. 277-287.

Nandhakumar, J. 1996. "Design for Success?: Critical Success Factors in Executive Information Systems Development," European Journal of Information Systems (5:1), pp. 62-72.

Negash, S., and Gray, P. 2008. Business Intelligence. Springer Berlin Heidelberg.

Olbrich, S., Poppelbuß, J., and Niehaves, B. 2012. "Critical Contextual Success Factors for Business Intelligence: A Delphi Study on Their Relevance, Variability, and Controllability," System Science (HICSS), 2012 45th Hawaii International Conference on IEEE, pp. 4148-4157.

Olszak, C. M., and Ziemba, E. 2012. "Critical Success Factors for Implementing Business Intelligence Systems in Small and Medium Enterprises on the Example of Upper Silesia, Poland," Interdisciplinary Journal of Information, Knowledge, and Management (7:12), pp. 129-150.

Poon, P., and Wagner, C. 2001. "Critical Success Factors Revisited: Success and Failure Cases of Information Systems for Senior Executives," Decision support systems (30:4), pp. 393-418.

Presthus, W., Ghinea, G., and Utvik, K.-R. 2012. "The More, the Merrier?: The Interaction of Critical Success Factors in Business Intelligence Implementations," International Journal of Business Intelligence Research (IJBIR) (3:2), pp. 34-48.

Rainer, R. K., and Watson, H. J. 1995. "What Does It Take for Successful Executive Information Systems?," Decision Support Systems (14:2), pp. 147-156.

Remus, U., and Wiener, M. 2010. "A Multi-Method, Holistic Strategy for Researching Critical Success Factors in It Projects," Information Systems Journal (20:1), pp. 25-52.

Rockart, J. 1979. "Chief Executives Define Their Own Information Needs," Harward Business Review (57), pp. 81-93.

Sangar, A. B., and Iahad, N. B. A. 2013. "Critical Factors That Affect the Success of Business Intelligence Systems (Bis) Implementation in an Organization," International Journal of scientific \& technology research (12:2), pp. 176-180.

Schieder, C., and Gluchowski, P. 2011. "Towards a Consolidated Research Model for Understanding Business Intelligence Success," ECIS.

Standing, C., and Cripps, H. 2015. "Critical Success Factors in the Implementation of Electronic Health Records: A Two-Case Comparison," Systems Research and Behavioral Science (32:1), pp. 75-85.

Tremblay, M. C., Hevner, A. R., and Berndt, D. J. 2012. "Design of an Information Volatility Measure for Health Care Decision Making," Decision Support Systems (52:2), pp. 331-341.

Wixom, B., and Watson, H. 2010. "The Bi-Based Organization," International Journal of Business Intelligence Research (1:1), pp. 13 - 28.

Wixom, B., and Watson, H. J. 2001. "An Empirical Investigation of the Factors Affecting Data Warehousing Success," MIS Quarterly (25:1), pp. 17-41.

Wu, J. 2007. "Critical Success Factors for Erp System Implementation," in Research and Practical Issues of Enterprise Information Systems Ii. Springer, pp. 739-745.

Yeoh, W., and Koronios, A. 2010. "Critical Success Factors for Business Intelligence Systems," Journal of computer information systems (50:3), pp. 23-32. 


\section{Acknowledgment}

We would like to express our gratitude to Bismi Jomon, Business Services Manager, and Annie Gilbert, Applications and Knowledge Management Director, at Alfred Hospital for providing their invaluable insight and expertise to this research. We would also thank Professor Chris Bain for his great support in the data collection process of this research.

Copyright: (c) 2018 Quy Nguyen, Rob Meredith, Frada Burstein. This is an open-access article distributed under the terms of the Creative Commons Attribution-NonCommercial 3.0 Australia License, which permits non-commercial use, distribution, and reproduction in any medium, provided the original author and ACIS are credited. 